\title{
O Imigrante e o Direito
}

Gustavo Zanini

"Imigração Italiana: sua importância histórica, os acordos vigentes entre Brasil e Itália e as propostas para maior entrosamento"

RESUMO: INTRODUÇÃO: Parte I - A Primeira Fase da Normatividade sobre a Imigração no Brasil. Parte II - Regime Jurídico da Imigração Italiana no Brasil - a) O Acordo de Colaboração entre Brasil e Itália. b) Os Acordos de Migração entre Brasil e Itália. c) O Acordo de Roma de 1960 sobre Assistência e Organização das Correntes Migratórias. d) O Acordo de Previdência Social. e) O Acordo sobre Serviço Militar. f) Acordo Cultural. CONCLUSÕES. NOTAS. BIBLIOGRAFIA.

\section{INTRODUÇĀO}

Um dos temas a ser examinado no VI Congresso Brasileiro de Imigração e Integração em São Paulo relativo à Imigração e Integração intitula-se "O Imigrante e o Direito".

Trata-se, em verdade, de capítulo deveras amplo dentro da problemática da imigração no Brasil, se considerarmos todas as vicissitudes históricas e sociais que ocorreram em relação a esse fato, desde o momento em que os primeiros contingentes de estrangeiros aportaram em nosso país. Por isso, este ensaio circunscreve-se aos imigrantes italianos.

Os critérios concernentes ao problema da imigração adotados pela Coroa portuguesa, no limiar do século XVIII, revelam as diretrizes reguladoras da matéria, cuja redação apresenta, aliás, forma bem singela. É o que se depreende do despacho de 22 de junho de 1729, emitido pelo Conselho Ultramarino da Metrópole lusa elaborado nos seguintes termos. "É conveniente que, se não instalando no Sul, nas povoaçōes da colônia e outras, casais de ilhéus, e quando estes forem insuficientes, se podiam conseguir casais estrangeiros, sendo alemães ou italianos e de outras nações que não sejam castelhanos, ingleses, holandeses e franceses'(1).

(1) CENNI, Franco. Italianos no Brasil. Liv. MARTINS Editora, São Paulo, 1958, p. 103. 
O mesmo critério de forma generalizada pode ser verificado no Decreto assinado a 25 de novembro de 1808 pelo príncipe Dom João VI, pelo qual se permitia a "concessão de 'sesmarias' também a estrangeiros para fim de criar condiçōes favoráveis à imigração espontânea"(2).

Com o perpassar do tempo, contudo, tornou-se necessário estabelecer medidas normativas apropriadas sobre o processo imigratório e sobre os direitos e obrigações dos imigrantes de modo a permitir que o desempenho desses objetivos pudesse acompanhar paralelamente a evolução global da sociedade brasileira, nesse período histórico, ainda em formação.

\section{PARTE I}

\section{A PRIMEIRA FASE DA NORMATIVIDADE SOBRE A IMIGRAÇĀO NO BRASIL}

As leis atinentes à imigração no Brasil surgem no decorrer do século XIX e estendem-se ao período atual, não apresentando as mesmas qualquer caráter de preferência a uma ou outra nacionalidade estrangeira. Trata-se de legislação que regulamenta os problemas de naturalização, serviço de transporte de imigrantes, criação de colônias, estado civil, o gozo dos direitos civis e o uso do passaporte.

O decreto no 397 , de 3 de setembro de 1846, por exemplo, criava facilidades para que os colonos de São Leopoldo e São Pedro de Alcântara se naturalizassem brasileiros. Para esse fim, nos termos do Art. 1을 exigia-se apenas que os interessados assinassem um "termo de declaração de ser essa a sua vontade", ato que, aliás, se registrava na respectiva Câmara municipal.

De particular interesse foi o advento da Lei no 1.096 , de 10 de setembro de 1860 , no que tange ao estado civil dos filhos de imigrantes. " $O$ direito que regula no Brasil o estado civil dos estrangeiros aí residentes, sem ser por serviço de sua nação, poderá também ser aplicado ao estado civil dos filhos desses mesmos estrangeiros durante a menoridade, e sem prejuízo da nacionalidade reconhecida pelo Art. 60 da Constituição. Logo que esses filhos cheguem à maioridade, entrarão no gozo dos direitos de cidadãos brasileiros, sujeitos às respectivas obrigaçōes, na forma da constituição e das leis".

Pelo que respeita à organização dos meios de deslocamento e acomodação, baixou-se o Decreto 3.254, de 20 de abril de 1864, de natureza nitida-

(2) CENNI, Franco. idem, p. 104. 
mente protetora. Segundo este Decreto, cria-se a "Agência Oficial de colonização com escritório no centro da cidade, hospedaria e todo o serviço de transporte, desembarque, alojamento e distribuição pelas colônias do Estado".

\section{-PARTE II}

\section{REGIME JURÍDICO DA IMIGRAÇĀO ITALIANA NO BRASIL}

Processou-se o início da colonização italiana no Rio Grande do Sul, entre 1871 e 1875, e durante algumas décadas naturalmente os problemas de ordem jurídica eram regulados, consoante se observou, por leis de caráter geral atinentes às migrações italianas e de outros países.

Entenderam, no entanto, os governos da Itália e do Brasil haver necessidade de uma reorganização desse movimento, considerado da maior relevância para as relaçōes interestatais. Para melhor promover essa reorganização, passaram, então, os governos dos dois países a celebrar acordos bilaterais específicos. Assim sendo, os primeiros instrumentos convencionais diziam respeito aos problemas da migração propriamente dita, e os acordos posteriores foram os relativos a questōes de colaboração recíproca, de serviço militar, de intercâmbio cultural e de previdência social. É para esses problemas que daremos nossa atenção nos capítulos subseqüentes.

\section{A) O Acordo de Colaboração entre Brasil e Itália}

Após a Segunda Guerra Mundial os problemas econômicos e sociais e por via de consequêência também os concernentes à migração, adquiriram uma relevância particular nas relaçōes internacionais. Constituiu uma preocupação fundamental e constante dos governos recorrer a novos instrumentos e mecanismos para a solução desses problemas, havendo sido, desde então, dispensados grandes cuidados à causa das migraçöes. De fato, foi com base nesses elementos que aos 8 dias do mês de outubro de 1949, firmou-se no Rio de Janeiro o Acordo entre Brasil e Itália para incentivar as relaçōes de colaboração recíproca e resolver as questōes atinentes ao Tratado de Paz, de 1947.

Segundo este Acordo de colaboração, o Governo brasileiro e o Governo italiano assumiram o compromisso de facilitar a imediata criação, bem como o desenvolvimento e as operaçōes de uma Companhia (Sociedade Anônima Brasileira) de colonização e Integração, cuja finalidade será a de promover e desenvolver o trabalho dos imigrantes italianos no Brasil. (Art. II)

Por outro lado, os dois governos declararam empenhar-se na celebração de um novo acordo, o qual tivesse por finalidade precisa regular e desenvolver a imigração no Brasil de elementos adequados às características $e$ às necessidades do País. E para esse fim estabelecer-se-iam no convênio de imigração as 
fórmulas mais apropriadas à recíproca colaboração entre os dois Países. (Art. VII)

\section{B) Os Acordos de Migração entre Brasil e Itália}

Tendo em conta os termos básicos consignados no Acordo de 1949, os governos do Brasil e da Itália iniciaram diversas consultas no sentido de realizar efetivamente uma obra simultânea de cooperação para conceder um tratamento adequado aos imigrantes. Os resultados imediatos desta ação conjunta refletem-se no Acordo de Migração entre Brasil e Itália (através de Notas trocadas entre as duas Altas Partes Contratantes), assinado no Rio de Janeiro a 5 de julho de 1950. As Ratificaçōes foram trocadas no Rio de Janeiro a 28 de abril de 1952 e o Acordo foi promulgado pelo Decreto 30.824, de 7 de maio de 1952.

Nesse instrumento os dois Governos estabelecem as normas gerais que devem reger as soluçōes dos problemas migratórios e de colonização a eles vinculados. E dessa forma os dois Governos prevêem o advento de vantagens para ambos os Povos da orientação e da disciplina das correntes migratórias italianas para o Brasil. (Art. 1o - Introdução)

Quanto às condiçōes relativas à execução do processo migratório entenderam os signatários que elas teriam caráter revestido de amplas facilidades. Com efeito, "A imigração de italianos para o Brasil" - estipula o Art. II - "acompanhado ou não de suas famílias, é permitida pelas Altas Partes Contratantes quer sob a forma de migração espontânea baseada em Carta de chamada familiar ou em oferta de trabalho, quer sobre a forma de transferência de sociedades, de cooperativas ou de grupos de trabalho, condicionada à aprovação de seus programas pelas Autoridades brasileiras e italianas competentes, quer ainda sob a forma de migração dirigida, baseadas em listas acordadas para cada leva pelos representantes de ambos os Governos".

\section{C) O Acordo de-Roma de 1960 sobre Assistência e Organização das Correntes Migratórias}

Decorreram então dez anos de experiências desde o Acordo do Rio de Janeiro, com resultados bastante expressivos neste assunto. $\mathrm{Na}$ medida em que a obra da imigração se desenvolvia e abrangia novas e mais complexas áreas operacionais, tornou-se peremptório imprimir uma reformulação da mesma, para que se lograssem, em verdade, mecanismos mais dinâmicos e instituições mais ajustadas às necessidades atuais.

Em estrita conexão com as medidas anteriores os Governos do Brasil e da Itália assinaram um novo documento convencional. Foi o Acordo de Migração 
pactuado em Roma, a 9 de dezembro de 1960 - promulgado ao depois, pelo Decreto 57.759, de 8 de fevereiro de 1966.

Predominaram neste Acordo as idéias da assistência e da organização das migraçōes condizentes com os respectivos interesses baseados no espírito de colaboraçāo internacional.

No que tange às finalidades, o Acordo de Röma de 1960, tem por objetivo orientar, assistir e organizar as correntes migratórias italianas para o Brasil dentro de um regime de conjugação de esforços de ambas as Altas Partes Contratantes, a fim de que os problemas migratórios e de colonização entre os dois Países tenham solução prática, rápida e eficaz, levando-se em conta a conveniência de preservar a unidade dos núcleos familiares. (Art. 19) Este Acordo também delara que a migração italiana para o Brasil poderá ser dirigida ou espontânea em colaboração e assistência com o Comitê Intergovernamental para as Migrações Européias (CIME) e com outros organismos Internacionais. (Art. 29)

\section{D) $O$ Acordo de Previdência Social}

O Acordo Administrativo de Previdência Social entre Brasil e Itália, firmado em Brasília a 19 de março de 1973 - para dar aplicação aos artigos 37 a 43 do Acordo de Roma, de 1960 - contempla um interessante procedimento geral do regime jurídico de concessão de prestaçōes por motivo de doença, invalidez, morte (pensão), maternidade e funeral.

Segundo o Art. 3, desse Acordo, para os fins de concessão previstas para o trabalhador segurado e seus dependentes, o País de acolhimento levará em conta, quando necessário, os períodos de seguro cumpridos no País de origem.

Em um texto de onze artigos, o Acordo Administrativo de Brasília entrou em vigor, com efeitos retroativos a partir de 26 de fevereiro de 1965, data em que o Acordo de Migração iniciou sua vigência ${ }^{(3)}$.

\section{E) O Acordo sobre Serviço Militar}

Outra das grandes deficiências existentes nas relaçōes entre o Brasil e a Itália podia ser notada na falta de um instrumento jurídico relativo ao serviço militar. Para sanar essa lacuna, os dois Governos firmaram o Acordo sobre Serviço Militar, no Rio de Janeiro, a 6 de setembro de 1958, o qual foi promulgado pelo Decreto 56.417, de 4 de junho de 1965.

(3) Vide SÜSSEKIND, Arnaldo. Tratados ratificados pelo Brasil. Biblioteca Jurídica Freitas Bastos, Rio de Janeiro, 1981, p. 334. 
Este Acordo expressa o propósito dos dois Governos no sentido de atribuir uma consideração especial às pessoas que estejam ou venham a ficar sujeitas a prestar serviço militar obrigatório, nas Forças Armadas de ambos os Países. (Art. 19)

\section{F) Acordo Cultural}

O ano de 1965 marca uma outra etapa importante nas relações entre o Brasil e a Itália na esfera da cooperação cultural. O programa dessa cooperação foi consubstanciado no Acordo cultural firmado no Rio de Janeiro, a 6 de setembro de 1965 e entrado em vigor a 23 de julho desse ano.

Demonstra o exame desse Acordo que os Governos brasileiro e italiano, cônscios da comunidade de tradições sobre as quais se baseia a vida cultural de seus dois países, e animados do desejo de tornar ainda mais estreitas e fecundas as relaçōes literárias, artísticas, científicas e técnicas já existentes entre seus dois povos, permitiräo a criação de instituições culturais. Além disso, cada governo favorecerá junto às Universidades, aos outros institutos superiores e aos institutos de instrução média situados no próprio território, a criação de cátedras, leitorados e cursos de língua, literatura, história, e arte de outro País. (Art. II) Para a realização desses planos manter-se-ão contatos diretos entre as universidades e outros organismos de cultura humanística, científica e artística dos dois Países, impondo-se, necessariamente, nessas atividades o intercâmbio de professores, de conferencistas, de pesquisadores e de estudantes. (Art. IV)

\section{CONCLUSŌES}

Da análise efetuada neste ensaio depreende-se, desde logo, existir, a partir do século XIX, profundos vínculos de amizade e de colaboração entre o Brasil e a Itália. Tais vínculos amadureceram pelas experiências nos vários campos de atividade e se solidificaram de modo inabalável.

Tendo em conta esses fatores, desejamos assinalar em nossas consideraçōes conclusivas que os Governos dos dois países detêm os pressupostos para a elaboração de uma convenção sobre igualdade de direitos e deveres entre brasileiros e italianos. O elemento fundamental para esse objetivo já existe plenamente; é o ânimo voluntário de suscitar o gradual aperfeiçoamento, em todos os setores de seus relacionamentos dos instrumentos e estruturas destinados a lograr o harmonioso desenvolvimento da Comunidade Ítalo-Brasileira ${ }^{(4)}$.

(4) Vide GUALAZZI, Eduardo Lobo Botelho. Comunidade Ítalo-Brasileira. Artigo publicado no jornal "O Estado de S. Paulo", 7 de março de 1987 pp. 27 e 28. 


\section{BIBLIOGRAFIA}

CENNI, Franco. Italianos no Brasil. Liv. MARTINS Editora. São Paulo, 1958.

BUARQUE DE HOLANDA, Sérgio. "Raízes do Brasil". Liv. José Olímpio Edit., Rio de Janeiro, 1956.

CORTES, Geraldo de Meneses. Migração e Colonização no Brasil. Livraria José Olímpio Edit., São Paulo, 1958.

ASCARELLI, Tullio, Sguardo sul Brasile. Ed. A. Giuffrè, Milano, 1949. 